\title{
FROM LANGUAGE LEARNERS TO LANGUAGE USERS: STUDENTS' TRAJECTORIES IN AN ENGLISH-MEDIUM HIGHER EDUCATION CONTEXT
}

\author{
MARINE LAÍSA MATTE \\ Universidade Federal do Rio Grande do Sul
}

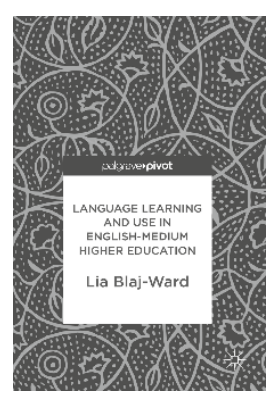

Blaj-Ward, L. (2017). Language learning and use in English-medium higher education. Cham, Switzerland: Palgrave Macmillan.

Language Learning and Use in English-Medium Higher Education published by Lia-Blaj Ward in 2017 invites the reader to follow the journey of international students on and off campus during university. Thus, both the subject of the book and the reading itself are journeys. This empirical research counts mainly on ethnographic methods and seeks to understand the EnglishMedium of Instruction (EMI) scenario through the lenses of the learners. Since this is an ethnographic work, through vignettes and narratives that the reader is familiarized participants' trajectories and feel very close to the setting under investigation. International students are the object of study of this volume and are referred to as EMI participants whose trajectories are worth analyzing in detail. The book is divided into seven chapters, the first being the introduction and the last one the conclusions.

Considering that a qualitative perspective is adopted in this research, the focus is on people rather than on numbers, which means that the author is more interested in the participants' perceptions of their own process of English language development. Topics such as "needs analysis", "immersion and instruction", "learner vs. user experience" are addressed throughout the book and are called key threads by the author. As she mentioned in the introduction, eight other texts shaped this volume and worked as an inspiration to the making process of the research as they all have similar topics: Norton and Toohey (2001), Benson et al. (2013), Kinginger (2009), Peter and Fernandéz (2013), Water and Leung (2013), Blair (2006), Dunworth et al. (2014), and Holliday (2016). 
The second chapter, Language Learner Histories: Points of Departure for University Study is one of the most interesting ones as the reader learns about the profile of the EMI participants and their previous experiences with the English language. Moreover, some features of EMI are provided throughout the reading. For instance, it is said that one of the basic principles of EMI is that English language development is a consequence of experiencing higher education (HE) in English, which is intimately related to language exposure. The argument sustained in the book is that these international students start their courses as language learners and little by little become language users who are able to meaningfully put into practice what they were taught in formal educational settings.

EMI is not simply teaching English for Academic Purposes (EAP) in a non-English speaking country. When it comes to using the language as a medium, it is more about focusing on learning strategies in which the language is a mere instrument. Therefore, even though the fundamentals of EAP as the English that is used by people in academic contexts (Hamp-Lyons, 2001; Hyland \& Hamp-Lyons, 2002) and EMI might be intertwined, the approaches in teaching have peculiarities. Considering that language development is interactive and nonlinear, being exposed to situations that simulate real life can become too artificial. In other words, this means that too much linguistic input in a classroom environment may hinder students' abilities in English when facing situations outside of it. This argument is presented by Kinginger (2013) for whom language learning process is individual with subjective nuances playing a crucial role.

Still in regards to the issues surrounding the "living abroad" and "studying in an EMI context" - which are the main topics covered in the book - the author argues that language learning histories say a lot about the way students develop in language while in HE. Thus, the students' background and their previous experiences in learning English influence how they perform in an EMI context. In the author's words, "It is not uncommon for students who perform well as language learners in classrooms in their home country to find the communicative demands in EMI settings quite challenging." (p. 24). For this reason, it is a "study abroad" opportunity that offers access to social spaces outside language classroom that also entails language development.

In the third chapter entitled Words, words, words, the discussion involves the fact that vocabulary poses difficulties in EMI settings, not exclusively the terminology of different areas of expertise, but also the so-called "academic vocabulary". Although there is a plethora of terms and meanings (Baumann \& Gravez, 2010), this general academic vocabulary is understood as words that are common to any field of knowledge. However, this notion is not widely accepted among scholars. The study of academic vocabulary is usually done through the use of Corpus Linguistics tools, as it is the case of the Academic Word List (Coxhead, 2000). Nevertheless, this type of list easily gets out of date and its learning is usually associated to memorization. Thus, when it comes to teaching academic words, it is preferred that teachers and tutors focus more on strategies to acquire new vocabulary, rather than only relying on ready-made lists. It is also the teachers' role as instructors (Folse, 2011) to create opportunities inside the classroom so that 
students are exposed to language input. Incidental learning may happen, and students are more prepared to use this language in naturally occurring situations.

A thought-provoking discussion surrounding the topic of vocabulary learning can be observed in the following excerpt:

Lexicographers put language into boxes; they devise categories for vocabulary items, build corpora and use tools to explore word frequency and behaviour, salience, keyness. Language tutors select appropriate vocabulary for their learners. Language learners and users, on the other hand, bring words alive by creating personally meaningful connections. (p. 46)

Furthermore, based on the participants' reports on how they learn vocabulary, they reveal having different ways of acquiring it. Likewise, their motivations vary, as some participants were really into understanding the lexical choices of a lecture in order to try to incorporate the new words into their own presentations, while for others the use of the words becomes natural even if they are not paying attention to the fact that they did not know how to fit the word into a sentence before.

Spoken English on the EMI campus entitles the fourth chapter and discusses if experiences regarding spoken English might be effective or not. Previous language use practices are one of the key aspects that lead to effectiveness in interactions. In terms of English teaching environment, traditional approaches do not emphasize the speaking ability. Additionally, textbooks usually have non-authentic texts, which make the language exposure somewhat artificial. The key thread is to focus on meaningful interactions in which spoken English is required. For instance, according to the author "learning and teaching events centered around practical, hands-on projects facilitated a greater degree of interaction." (p. 66). Group work can also enhance students' spoken abilities as it is a constructive interaction in which both English and personal identity develop and consolidate.

The fifth chapter, Reading Practices in Academic Settings, along with chapters 3 and 4, focuses on language use and language development outside a formal language classroom environment. The fifth chapter in particular debates the reading experiences required in HE. As "prior experiences of reading do not necessarily translate into effective reading at university without appropriate guidance" (p.81), it is crucial that reading is included in EAP/EMI teaching curricula. It is known that HE is embedded in the logic of "institutional practices of mystery" (Lillis, 2001), meaning that specific abilities and performances are expected from university students, at the same time that tutors and professors take these requirements for granted. Thus, in order to have students reading successfully, it is crucial that they develop critical literacy with the help of assignments that scaffold their reading processes (Evans \& Morrison, 2012). By transiting from previous reading experiences to academically sanctioned ways of reading, students can construct meaning and build knowledge outside of the texts in order to act critically and as citizenships in a globalized world.

Parameters of English Language Development Provision in EMI is the title of the sixth chapter which aims at discussing the relationship between language and academic achievement 
and the role students have in this regard. Studies that analyze language and academic achievement are usually based on quantitative measures, such as Knoch et al. (2015), Humphreys et al. (2012), and Storch and Hill (2008), to name a few. As far as EAP provision is concerned, the author argues that it must be context-sensitive and attend students' needs, who, in turn, must have an active role rather than a recipient one in the language learning process.

If language proficiency is everyone's business, implementing policies and building strategies are urgent demands. Furthermore, still reported in the sixth chapter, participants were asked about their needs and wants, and how their knowledge developed and what formal instruction they could apply to meet their needs in the EMI context analyzed. The most common answers included increasing fluency, gaining confidence and "thinking in English". Therefore, as the academic year passes by and more opportunities to practice language both inside and outside the classroom are offered, the more students enhance their English language proficiency. Going back to the title of the chapter in question,

to be successful, formal provision needs to articulate with EMI participants' prior and future experiences, to empower EMI participants to capitalise on (formal and informal) resources available, and to engage them in the decision-making processes around institutional resource deployment. Additionally, formal provision needs to be embedded within a culture of quality that favours contextual sensitivity. (p. 118)

To conclude this review, the last comments meet the final topics addressed in the last chapter of Language Learning and Use in English-Medium Higher Education. The book is a delightful read that narrates the students' personal journeys of language learning in an EMI context. Considering that the discussion revolves around students going from language learners to language users both on and off campus, the qualitative research that originated the book sheds light on the debate about what may help or hinder EMI participants' growth into competent and confident communicators through the use of English(es). Even though the discussion is relevant, it is not finished yet; thus, the author poses some questions to close the book and invites the reader to further reflect on them:

- How do successful EMI participants mobilize available resources to develop confidence in expertly contributing to dialogue in their chosen fields?

- Which aspect of EAP course design should be highlighted and made more transparent and is most likely to impact on EMI participants' willingness to engage with formal EAP provision?

- What do EAP practitioners need to unlearn from their prior professional development in order to conduct and apply insights from needs analysis that are sufficiently fine-tuned to EMI participants' transition from language learner to language user?

In conclusion, it is worth mentioning that this reading is highly recommended for those interested in the subject. It is definitely a rich description of what and who is involved in an English-Medium Higher Education. 


\section{References}

Baker, W. (2016). English as an academic lingua franca and intercultural awareness: Student mobility in the transcultural university. Language and Intercultural Communication, 16(3), 437-451. doi:10.1080/14708477.2016.1168053

Baumann, J. F., \& Graves, M. F. (2010). What is academic vocabulary? Journal of Adolescent \& Adult Literacy, 54(1), 4-12.

Benson, P., Barkhuizen, G., Bodycott, P., \& Brown, J. (2013). Second language identity in narratives of study abroad. Basingstoke: Palgrave.

Blair, B. (2006). At the end of a huge crit in the summer, it was 'crap' - I'd worked really hard but all she said was 'fine' and I was gutted. Art, Design and Communication in Higher Education, 5(2), 83-95. doi:10.1386/adch.5.2.83/1

Coxhead, A. (2000). A new academic word list. TESOL Quarterly, 34, 213-238. doi: $10.2307 / 3587951$

Dunworth, K., Drury, H., Kralik, C., \& Moore, T. (2014). Rhetoric and realities: on the development of university-wide strategies to promote student English language growth. Journal of Higher Education Policy and Management, 36(5), 520-532. doi:10.1080/1360080X.2014.936088

Evans, S., \& Morrison, B. (2012). Learning and using English at university: Lessons from a longitudinal study in Hong Kong. The Journal of Asia TEFL, 9(2), 21-47. Retrieved from http://www.asiatefl.org/main/download_pdf.php?i=96\&c=1419300097\&fn=9_2_02.pdf

Folse, K. (2011). Applying L2 lexical research findings in ESL teaching. TESOL Quarterly, 45(2), 362-369. doi:10.5054/tq.2010.254529/epdf

Hamp-Lyons, L. (2001). English for Academic Purposes. In D. Nunan, \& R. Carter (Eds.), The cambridge guide to teaching English to speakers of other languages (pp. 126-130). Cambridge, New York, Melbourne, Madrid: Cambridge University Press.

Holliday, A. (2016). Doing and writing qualitative research (3rd ed.). London: Sage.

Humphreys, P., Haugh, M., Fenton-Smith, B., Lobo, A., Michael, R., \& Walkinshaw, I. (2012). Tracking international students' English proficiency over the first semester of undergraduate study. IELTS Research Reports Online Series, 1, 1-41.

Hyland, K., \& Hamp-Lyons, L. (2002). EAP: Issues and directions. Journal of English for Academic Purposes, 1(1), 1-12.

Jenkins, J. (2013). English as a lingua franca in the international university: The politics of academic English language policy. Abingdon: Routledge.

Kinginger, C. (2009). Language learning and study abroad: A critical reading of research. Basingstoke: Palgrave Macmillan.

Kinginger, C. (2013). Introduction: Social and cultural aspects of language learning in study abroad. In C. Kinginger (Ed.), Social and cultural aspects of language learning in study abroad (pp. 3-15). Amsterdam: John Benjamins. 
Knoch, U., Rouhshad, A., Oon, S. P., \& Storch, N. (2015). What happens to ESL students' writing after three years of study at an English medium university? Journal of Second Language Writing, 28(1), 39-52.

Lillis, T. M. (2001). Student writing: Access, regulation, desire. Literacies. UK: Routledge.

Norton, B., \& Toohey, K. (2001). Changing perspectives on good language learners. TESOL Quarterly, 35(2), 307-322. doi:10.2307/3587650

Peters, P., \& Fernández, T. (2013). The lexical needs of ESP students in a professional field. English for Specific Purposes, 32, 236-247. doi:10.1016/j.esp.2013.05.002

Storch, N., \& Hill, K. (2008). What happens to international students' English after one semester at university? Australian Review of Applied Linguistics, 31(1), 04.1-04.17.

Waters, J. L., \& Leung, M. (2013). Immobile transnationalisms? Young people and their in situ experiences of 'international' education in Hong Kong. Urban Studies, 50(3), 606-620. doi:10.1177/0042098012468902 